\title{
Corrigendum
}

\section{Atomoxetine Enhances Connectivity of Prefrontal Networks in Parkinson's Disease}

\author{
Robin J Borchert, Timothy Rittman, Luca Passamonti, Zheng Ye, Saber Sami, Simon P Jones, \\ Cristina Nombela, Patricia Vázquez Rodríguez, Deniz Vatansever, Charlotte L Rae, Laura E Hughes, \\ Trevor W Robbins and James B Rowe
}

Neuropsychopharmacology (2016) 4I, 21 88; doi:I0.I038/npp.2016.46

Correction to: Neuropsychopharmacology advance online publication, 2 March 2016; doi:10.1038/npp.2016.18

Following the publication of this paper, the authors have changed the Funding and Disclosure section to read as follows:

This work was funded by the Wellcome trust (103838), Parkinson's UK, National Institute for Health Research's Cambridge Biomedical Research Centre and the Medical Research Council (MC_US_A060_0016 and RG62761), and the James F McDonnell Foundation (21st century science initiative on Understanding Human Cognition). The BCNI is supported by a joint award from the Wellcome Trust and Medical Research Council.

TWR reported receiving grants from GlaxoSmithKline, Lilly and Lundbeck; consulting fees from Merck, GlaxoSmithKline, Lundbeck, Lilly, Teva, Shire, Otsuka, and Cambridge cognition; honorarium from Springer-Verlag for Psychopharmacology editorial duties; and payments from Cambridge Cognition for Cambridge Neuropsychological Test Automated Battery (CANTAB). The authors declare no conflict of interest. 